\title{
The use of Visual Analog Pain Scales in Black Widow Spider Envenomation
}

\section{Dear Editor,}

Lactrodectism is the painful syndrome of muscle cramps produced by black widow spider envenomation. This syndrome progressively worsens over several hours. There are no specific tests that assess the severity of Latrodectism or its course. We are presenting a case of Latrodectism that was successfully managed using a visual analog pain scale (VAS). In the Emergency Department, pain severity scales are widely used to assess pain and monitor treatment. Pain scales such as the VAS have been validated for headache, long bone fracture, and abdominal pain.

\section{CASE REPORT}

A 17-year-old male, weighing $150 \mathrm{lbs}$. was presented to the Emergency Department (ED) after stating that a spider had bitten him. The incident occurred while he was sleeping. He awoke from a sleep after feeling an itching and burning sensation on his back. He went to the bathroom where he noticed a red mark on his lower right back. The patient returned to his bed and found a dead black widow spider. Soon after the bite, he felt tightness in his chest and experienced difficulty in breathing. Upon presentation to the $\mathrm{ED}$, he complained of severe cramping in both thighs and continued to experience difficulty in breathing. The patient reported that the tightness in his chest made speaking difficult. He denied any sensation of throat swelling, difficulty in swallowing, nausea, vomiting, or abdominal pain. A review of systems was otherwise negative. He was on no medications and had no drug allergies. Prior to the bite, the boy was healthy.

A physical examination of the young man showed a welldeveloped, alert, generally diaphoretic male in moderate distress that was secondary to pain. He was tachycardic with a heart rate of 102 beats/min, hypertensive with a blood pressure of $140 / 85 \mathrm{mmHg}$, and tachypneic with a respiratory rate of 20 breaths/min. His face was flushed and he had a facial grimace consistent with facies lactrodectisimus, the eyelids showing a slight bilateral ptosis. The patient spoke only during exhalation and in a grunting fashion. The abdomen was non-tender and rigid. The skin exam showed an irregular shaped, flat area of erythema $(1.5 \mathrm{~cm})$ with surrounding muscle fasciculations on the right lower back. No pilo-erection was noticed at the presumed bite sight. The examination was otherwise unremarkable and within normal limits.

\section{Course in the Emergency Department}

The patient brought the spider with him to the ED, and it was confirmed to be a black widow spider. Cardiac monitoring was performed and an intravenous line was established. The patient received three doses of morphine ( $2 \mathrm{mg}$ each) and a single dose of diazepam $(5 \mathrm{mg}$ ) over a period of one hour, but reported minimal relief from the medications and appeared to be in moderate to severe distress. His blood pressure had increased from $140 / 85 \mathrm{mmHg}$ to $160 / 95 \mathrm{mmHg}$, and his heart rate was $110-115$ beats/min. The decision was made to proceed with antivenom treatment. An initial VAS was performed using a $100 \mathrm{~mm}$ rule and noted to be $33 \mathrm{~mm}$. Antivenom was ordered and a skin test was prepared. A second VAS was performed 30 minutes later, and it showed a score of $30 \mathrm{~mm}$. Vitals were taken and recorded: BP: 150/74 mmHg, RR: 16 bpm, HR: $110 \mathrm{bpm}$. After confirming a negative skin test for hypersensitivity, one vial of Merck Latrodectus mactans Antivenin was administered. The antivenom was infused over 60 minutes. The patient appeared to become much more comfortable approximately after one-half of the infusion was completed. The VAS score, immediately after the antivenom infusion, was $7 \mathrm{~mm}$ with a heart rate of $103 \mathrm{bpm}$ and a blood pressure of $106 / 56$. The patient stated that the pain was subsiding. He was monitored for two more hours and was eventually discharged without further complications. A follow up was preformed via telephone five days after treatment. The mother of the patient reported that her son was doing well. He did not show any further signs of symptoms.

\section{DISCUSSION}

Envenomation by the black widow spider (genus Latrodectus) is a common occurrence across the continental U.S. and Hawaii. The clinical effects of Latrodectus envenomation include hypertension, diaphoresis, muscle cramping, weakness, and gastrointestinal complaints. Intractable pain is the primary reason a victim of Latrodectus envenmoation reports to a health care facility (1). Many individuals describe the pain as nonspecific cramping of the extremities, back, and abdomen. Some compare the intensity of pain to nephrolithiasis or childbirth (1). It is the assessment of this nonspecific pain and its presence or absence that currently guides our treatment choices.

Titration of opioid pain medication is the typical initial treatment for black widow spider envenomation. If opiates do 
not result in sustained relief, then the antivenom should be considered. Because patients' responses may vary, a systematic form of measurement would aid in the assessment of complex cases. We suggest that the VAS should offer a convenient, standardized tool for this measurement. The VAS pain score has been validated as a useful diagnostic for the assessment of changes in acute pain in multiple ED based studies, $(2,3,4)$, including many that involve the musculoskeletal system $(5,6)$.

Our patient demonstrated a significant change in the VAS score after treatment with antivenom. The change was associated with a clinical improvement that was noticed by the patient and the treating physicians. We therefore propose its use in future treatment trials to improve the reliability and objectivity of pain assessment.

\section{Thank you,}

Jody J. Rogers, M.D. (777 Bannok St., MC 0180, Denver, CO 80204-4028)

Chriss Stanford, M.A.

Richard C. Dart, M.D., Ph.D.

\section{REFERENCES}

1. Clark RF. The Safety and Efficacy of Antivenin Latrodectus mactans. J. Toxicl. Clin. Toxicol. 2001; 39(2): 125-127

2. Gallagher JE, Bijur PE, Latimer C, Silver W. Reliability and Validity of a Visual Analog Scale for Acute Abdominal Pain in the ED. Am. J. Emerg. Med. 2002; 20: 287-290.

3. Gallagher JE, Libman M, Bijur PE. Prospective validation of Clinically important Changes in Pain severity measured on a Visual analog Scale. Ann Emerg. Med. 2001; 38: 633-38.

4. Todd KH, Funk KG, Funk JP, Bonacci R. Clinical Significance of Reported Changes in Pain Severity. Ann. Emerg. Med. 1996; 27 : 485-9.

5. Tuzun F, Unalan H, Oner N, Ozguzel H, Kirazil Y, Icagosioglu A, et. al.; Multicenter, Randomized, Double-blinded, Placebo-controlled trial of Thiocolchicoside in Acute Low Back Pain. Joint Bone Spine 2003; 70: 356-361.

6. Mork H, Ashina M, Bendtsen L, Olesen J, Jensen R. Experimental Muscle Pain and Tenderness Following Infusion of Endogenous Substances in Humans. European Journal of Pain 2003; 7: 145-153. 